Revue d'histoire de l'Amérique française

ANG REVUE D.HISTOIRE DE L'AMÉRIQUE FRANÇAISE

\title{
Définition du libéralisme et de l'ultramontanisme comme idéologies
}

\section{Jean-Paul Bernard}

Volume 25, numéro 2, septembre 1971

URI : https://id.erudit.org/iderudit/303068ar

DOI : https://doi.org/10.7202/303068ar

Aller au sommaire du numéro

Éditeur(s)

Institut d'histoire de l'Amérique française

ISSN

0035-2357 (imprimé)

1492-1383 (numérique)

Découvrir la revue

Citer cette note

Bernard, J.-P. (1971). Définition du libéralisme et de l'ultramontanisme comme idéologies. Revue d'histoire de l'Amérique française, 25(2), 244-246.

https://doi.org/10.7202/303068ar d'utilisation que vous pouvez consulter en ligne.

https://apropos.erudit.org/fr/usagers/politique-dutilisation/ 
DÉFINITION DU LIBÊRALISME ET DE L'ULTRAMONTANISME COMME IDÉOLOGIES

\author{
Jean-Paul Bernard \\ Département d'histoire \\ Université du Québec \\ à Montréal
}

La question du libéralisme et de l'ultramontanisme québécois au XIX $\mathrm{XI}^{\mathrm{e}}$ siècle renvoie d'abord à la guerre d'idées qui opposa le clergé et particulièrement des évêques comme Mgr Bourget et Mgr Laflèche aux Rouges, à l'Institut canadien de Montréal et aux journaux comme L'Avenir et Le Pays.

Mais il faut remarquer qu'il y eut là plus qu'un grand débat où s'affrontèrent les grands courants de pensée européens de l'époque. Le fait que toute l'histoire politique (partis, programmes et campagnes électorales) de la période 1848-1870 ait été dominée par cette question souligne que l'enjeu dépassait celui d'une simple joute intellectuelle et correspondait à la compétition pour le pouvoir au sein de la société canadienne-fran- 
çaise. Dans cette perspective il faut considérer l'ultramontanisme et le libéralisme comme des idéologies et définir leur rapport aux classes sociales. Des idéologies ou des définitions cchérentes et systématiques, par des groupes structurés, de la situation de cette société, de son avenir et des moyens d'y arriver.

Dans un sens positif, et le libéralisme et l'ultramontanisme rendent compte ou contiennent des éléments d'explication de la situation du Canada français; ils visent à l'intégration et à la mobilisation nécessaires à l'action. Mais en même temps, comme toute idéologie, ils tendent à justifier ou à légitimer la place et le rôle des groupes sociaux définiteurs dans la structure sociale: ils constituent des "mystifications" tendant à identifier l'intérêt particulier du groupe définiteur et l'intérêt général de toute la société.

La question du libéralisme et de l'ultramontanisme se posa durant tout le $\mathrm{XIX}^{\mathrm{e}}$ siècle mais la période $1848-1870$ constitua un moment privilégié pour la formulation et l'affrontement de ces deux idéologies. L'échec de 1837 et l'Union de 1840 avaient provoqué un nouvel équilibre des forces, une clarification des alignements et, du même coup, une décantation au plan des idéologies.

On verra apparaître, d'une part, chez une fraction de la petite bourgeoisie canadienne-française un conservatisme qui se dit satisfait de l'abandon du projet d'assimilation et de la place accordée aux Canadiens français dans les institutions politiques réformées grâce à l'avènement du gouvernement responsable. Cette fraction de la petite bourgeoisie considère comme un fait accompli l'Union, et avec l'Union la mise en minorité du Canada français et la fin, dès 1840 , de la possibilité pour une majorité française à l'Assemblée de contrecarrer les initiatives de la grande bourgeoisie anglaise. Elle accepte de collaborer à l'édification d'une économie canadienne fondée sur le commerce et sur l'appui des capitaux britanniques. Elle se réjouit de l'originalité en terre américaine d'un Canada héritier des traditions politiques et sociales de la Grande-Bretagne, regardant avec suspicion et les idées républicaines françaises et le "nivellement américain". A la limite elle accepte une situation dans laquelle domine la grande bourgeoisie anglophone, qui tend à faire du Canada français une masse rurale maintenue en dehors des grands échanges économiques, mais qui ne met pas en question son propre rôle politique et social.

D'autre part, chez une autre fraction de la petite bourgeoisie, s'exprime un libéralisme qui refuse l'Union et préconise le 
maintien d'un Bas-Canada distinct, habité et gouverné par des Canadiens français. Cette fraction de la petite bourgeoisie est attentive au spectacle du dynamisme américain et à celui des révolutions européennes. Répudiant le modèle britannique, elle prône une démocratisation radicale du système politique et de la société. Au plan économique elle met de l'avant, comme priorité, l'amélioration de l'agriculture canadienne-française et l'intégration de cette agriculture à l'économie des Etats-Unis.

Les positions de la fraction conservatrice de la petite bourgeoisie représentaient la paix, la stabilité, la fin des ambiguïtés qui avaient conduit au soulèvement de 1837. Par ailleurs le régime de l'Union lui-même, grâce à des concessions de type fédéral, laissait saufs les intérêts de la religion et du clergé en permettant à celui-ci, par exemple, de conserver le système des dîmes et d'étendre son rôle dans le système scolaire. De là la liaison, contre les libéraux, entre les conservateurs et le clergé.

C'est dans ce contexte qu'il faut placer les grands débats des années 1818=1870 et l'issue même de ces débats, l'écrasement du rougisme et son remplacement, après 1870, par un "libéralisme" purement politique et partisan (celui de Laurier, de Mercier ou de Marchand). Le libéralisme de la fin du siècle est bien loin, en effet, du "libéralisme véritable" - l'expression est de Arthur Buies - et bien près du conservatisme lui-même. La situation du Canada français après l'Union avait rendu difficile aux Rouges la conciliation du nationalisme et de l'idée démocratique (majorité et Canada français ne coïncidant plus) et désarmé leur anticléricalisme en donnant au clergé le statut d'élite essentielle à la conservation de la nationalité menacée de l'extérieur. Au contraire, cette situation avait favorisé l'influence du conservatisme et de l'ultramontanisme. Une société qui vivait dans l'ensemble d'une agriculture peu intégrée au grand commerce et qui était encadrée par une petite bourgeoisie aux horizons et aux ambitions très limités était manifestement un milieu propice à l'emprise d'une idéologie qui de façon générale valorisait le passé: la vie rurale, les relations sociales et les pratiques politiques de type familial, l'union étroite de l'Eglise et de l'Etat et la subordination de celui-ci à celle-là, enfin, dans le contexte canadien, la solidarité étroite de la conservation de la nationalité canadienne-française et de la conservation de la religion catholique. On comprend en lisant des textes comme ceux de Léon Gérin sur les milieux agricoles canadiens-français le succès des lettres pastorales de Mgr Bourget et le discrédit final des discours prononcés à l'Institut canadien. 